\title{
Problem-Based Learning in the English Language Classroom
}

\author{
Normala Othman ${ }^{1} \&$ Mohamed Ismail Ahamad Shah ${ }^{2}$ \\ ${ }^{1}$ Department of English Language and Literature, College of Arts, King Saud University, KSA \\ ${ }^{2}$ Department of English Language and Literature, International Islamic University Malaysia, Malaysia \\ Correspondence: Dr. Mohamed Ismail Ahamad Shah, Departmentt of English Language and Literature, \\ International Islamic University Malaysia, Malaysia. E-mail: ismailiium@yahoo.com
}

Received: December 26, 2012 Accepted: February 20, 2013 Online Published: February 22, 2013

doi:10.5539/elt.v6n3p125 URL: http://dx.doi.org/10.5539/elt.v6n3p125

\begin{abstract}
The purpose of this study was to investigate the effects of the problem-based learning approach (PBL) on students in language classes in two areas: course content and language development. The study was conducted on 128 students, grouped into the experimental and control groups, and employed an experimental research design. The syllabus, textbook, and instructor were controlled for both groups. The findings of the study showed that in terms of course content, both groups improved but in terms of language the PBL group showed more improvements. The PBL group showed improvements in the post-writing test, that is, their essays were richer in terms of support and arguments for each point, while the non-PBL did not show much difference in their post-writing test. This indicates that students could still acquire the course content with minimal content instruction. The limitations of the study and suggestions for further research are offered at the end of the paper.
\end{abstract}

Keywords: Problem-Based Learning, traditional approaches, Content-Based Instruction, proficiency

\section{Introduction}

The need to try new approaches to teaching language in Malaysia has become increasingly urgent, since the general complaint published almost every day in the media regarding the English language for the last few decades points to the deterioration of proficiency especially among the youths, despite the years they toiled learning the language at school. This has also taken its toll in the working sector where potential employers claim that school-leavers fare badly in their communication and writing skills, particularly in English (Nor Hartini, 2006; Zaharuddin, 2007) and in the private sectors due to the need to correspond with foreign counterparts around the world.

Given the barrage of learning and activities the students and teachers typically face each day, there appears to be no room to introduce a new approach in teaching and learning. Nonetheless, we would still advocate the language classroom as one of the first places to address the problem of declining English standards among ESL learners. Previous trends in teaching the English language, particularly to second or foreign language learners, have included grammar-translation method, the audio-lingual approach, communicative language teaching and task-based learning (Larsen-Freeman \& Anderson, 2011). In a recent research in ELT in Malaysia, Ting, Mahadhir and Chang (2010) proposed role play as a viable alternative to the traditional method of teaching, when they found their students showing improvements in proficiency towards the end of the course using this approach in their teaching.

Another alternative which is the focus of the current research is Problem-based learning (PBL), an approach which is certainly not a new teaching methodology. The model for PBL emerged from a number of medical schools especially the Case Western Reserve University in the United States of America in the 1950s and McMaster University Faculty of Health Sciences in Canada in the late 1960s (Barrows and Tamblyn, 1980; Boud and Feletti, 1994). The concern at that time was on the effectiveness of traditional science courses in preparing students for the real world and problems they would have to solve as physicians. Other concerns included students' lack of critical thinking skills in class and beyond, and courses being too focused on content, the latter easily causing boredom among students and 'burnt-outs' in them as well as teachers (Tan, 2003). In the humanities, it is still slowly being experimented, but in language it is going at a snail-pace, probably due to the fact that English language is a non-content subject and teachers tend to spend time on the prescriptive aspects of the language. This is evident in the dearth of PBL research published in language (e.g. Mardziah Hayati, 2005). 
Before going further, we need to provide a concept for PBL. In a nutshell, PBL is an approach that involves no teaching; students learn by solving problems that are carefully constructed by the teacher according to the course syllabus assigned to them throughout the semester. The teacher facilitates the process by putting the students in groups, scheduling presentations and preparing evaluation forms for the students to evaluate themselves and their peers, in addition to teacher evaluation. In PBL, the problem comes first, and an essential element of PBL is that content is introduced in the context of complex problems that imitate real life (Boud and Feletti, 1997). In contrast, most traditional and current teaching approaches present concepts and rules first, usually in a lecture format. This is the standard technique of teaching in most contemporary classrooms in Malaysia as teachers adhere strongly to the priority of preparing learners for examinations.

Traditional programmes of education and training usually put tremendous emphasis on content (Tan, 2003). In Malaysia, for example, it is a national pre-occupation to produce high-achieving students with a string of A's in national examinations. In addition, teachers must adhere very closely to the standardised syllabus administered by the Ministry of Education. Due to these factors, teachers would not think even remotely about switching approaches, especially to one that completely does away with instruction such as the PBL. The focus of teaching is to impart content knowledge, and teachers would perceive using extraordinary approaches as compromising or even sacrificing this major learning outcome. Hence, the current study was carried out to particularly investigate if acquisition of course content is indeed compromised when the PBL approach is used. In addition, it will analyse if students' proficiency may improve as advocated by the approach and previous studies.

So how does learning take place in the PBL approach when the students receive no instruction? In the PBL class, when the students work with each other to solve complicated and authentic problems, they are expected to be so absorbed in the tasks that they will not only increase their content knowledge but simultaneously enhance their communicative and thinking skills as they communicate, reason, assess the problem(s) at hand and solve them. Watson $(2001$, p. 3) explains that in PBL, "students work with classmates to solve complex and authentic problems that help develop content knowledge as well as problem-solving, reasoning, communication, and self-assessment skills". Thus, in a problem-based classroom, the process is crucial as that is where real learning actually takes place. The outcome is important too, and as learners acquire and develop the skills mentioned above, there will be opportunities for these learners to apply those skills across the disciplines in the long term. In PBL, students take charge of their education while emphasising critical thinking skills, understanding, learning how to learn and working cooperatively with others (White, 1996). These skills are not overtly developed or used in the traditional teacher-centred classroom and as a result, students do not become self-directed in their learning and continue to rely too much on being fed information by others.

The problem-solving tasks involve collecting data to solve the problem in the best possible manner. This involves a huge amount of reading by the students from every possible resource such as reading up books in the library and assessing databases. They may also interview experts in the field, and this would mean bringing the students closer to the real world. The PBL approach has become particularly convenient when advances in computing technology are accessible and a variety of reading materials are available online (Evensen and Hmelo, 2000). The Internet provides a wealth of information, and this makes it easier for the teachers to adopt the PBL approach in language learning and allow students to take control of their own learning.

Since we did not find much published empirical research on PBL in the English language course, we looked at its application in other subjects. For example, Kam and Chi (2007) observed students' extra-curricular activities done via PBL and noted that PBL is motivated by learning outcomes such as acquisition of knowledge and skills; their subjects showed, or perceived, positive development in both. This is true in a variety of subjects where PBL was adopted, even in physical education, as shown in a study carried out by Shih et al. (2007), who found that fifth grade students showed no differences in critical thinking in the pre- and post-tests but showed marked changes in the movement skill performance. One important learning outcome of PBL is language competence, as mentioned, which has been the focus of many PBL research across subjects, e.g., nursing and staff development (Chunta \& Katrancha, 2010), engineering (Lappalainen, 2010; Ng, 2008), and library science (Chen \& Chen, 2010), among others. To summarise, research done on PBL has highlighted several benefits, which include: (1) language skills, particularly useful in the Malaysian contexts; (2) communicative skills, particularly among those who do not have much opportunity to speak up in a teacher-centred classroom; (3) reading skills; (4) critical thinking skills; (5) collaborative learning, and (6) social skills. Along with these, as advocated by the approach and mentioned in the review, students are nurtured to become life-long independent learners.

What sets PBL apart from other task-based methodology is that with PBL, the teacher does not teach content. He or she gives out the problem first, followed by a brief explanation of the problem. The teacher facilitates the students' learning process and provides explanations which gradually introduce the task according to the course 
syllabus. The students are then assigned into groups, where they discuss and distribute research tasks to each other; these tasks often involve extensive and intensive reading of various resources-library, internet (web-based sources), books. The students may also opt to interview experts in the field. After a certain time, often a week, the research output or the data collected from their readings are compiled and used to solve the problem, which is often long, based on real-life situations, and created in a way that would engage students' curiosity to learn the subject matter in a meaningful manner (Tan, 2003).

As a PBL course features minimal teaching, the teacher must be adept in handling PBL classes, which may be a bit daunting at the beginning in formulating the problems, according to George Watson of the Institute for Transforming Undergraduate Education. (Note 1) However, Allen, Duch \& Groh (1996) earlier proposed that teachers could initially choose to have a mix of teaching and PBL, that is, they could engage in teaching now and then in delivering the course content. The idea is to encourage reluctant teachers to try out PBL rather than abandoning the method totally. Creating ill-structured problems that would sustain students' interest for a few weeks is difficult and generally time-consuming, but PBL advocates argue that in the beginning, the teacher will undoubtedly go through the laborious process of researching and creating their problems. Copland (2001 p. 3) who teaches PBL courses in the Prospective Principals Program in the School of Education at Stanford says, "the key thing in making [PBL] successful is the amount of time and energy that goes into the creation of the project. Finding a problem that really means something to the participants is absolutely critical". The nature of ill-structured problems, as suggested by Allen, Duch \& Groh (1996) and Gallagher (1997), should:

- contain multiple solution paths

- change as new information is obtained

- contain content that is authentic to the discipline

- generate interest and controversy and cause the learner to ask questions

- prevent students from knowing that they have made the "right" decision

- require more information for understanding the problem than is initially available

- be open-ended and complex enough to require collaboration and thinking beyond recall.

As mentioned, research in PBL in English language teaching is slowly emerging (Mardziah Hayati, 2005 \& Anton, 1990) and are more task-based and involves normal traditional teaching (Huang, 2010; Toth, 2008; Eckerth \& Siekmann, 2008). Despite the lack of research in the field of language per se, PBL has its merits as it is a move toward professional training; it gets students ready for the real world, as students are exposed to the following challenges and skills (Tan, 2003):

- Teamwork

- Independent learning

- Communication skills

- $\quad$ Problem-solving skills

- Interdisciplinary learning

- Information-mining skills

- Higher-order thinking skills

Since research in PBL in language courses are far and in between, this study, therefore, aims to address the gap in research on PBL in English language teaching, in general, and in content-based language teaching, in particular.

\section{Objectives of the Study}

The objectives of the study are to investigate the effects of PBL on:

1) students' acquisition of course content; and

2) students' language proficiency.

The first objective is to look at the students' acquisition of course content, as the teacher in the PBL classroom does not teach. With the amount of reading, communicating and writing involved, students would be exposed to the content as they read, gather and sort their data to solve the problems. If PBL is to be considered as an alternative to the traditional lecture approach, then the students in the PBL group should also acquire and/improve their language due to the amount of reading carried out for each task. Learning becomes meaningful 
due to self-learning instead of spoon-feeding by teachers. The self 'discovery' of knowledge in PBL will cause students to retain it better than when they learn it via spoon-feeding from teachers in the traditional approach.

\section{Research Questions}

To address the objectives of the study, the following research questions were formulated:

1) Is there a difference in the extent of content learned by both the PBL and the non-PBL groups?

2) To what extent does the PBL approach enhance the students' language proficiency?

\section{Methodology}

\subsection{Subjects}

The subjects of the study were 128 third-year IIUM undergraduate students enrolled in four sections of a language class that has a literature component in its syllabus. Classes were scheduled twice a week, 80 minutes per session. Discussions, class activities and group presentations were carried out in conventional classrooms, using the board, computer and LCD projector.

\subsection{Procedure}

The course had four sections, with 36 to 42 students per group. Two of the classes, comprising 64 students, followed the PBL approach, while the other two, again comprising 64 students, followed the traditional lecture and guided approach. The former formed the experimental group, while the latter the control group. The PBL classes were further grouped into teams of four students; one class had nine groups, and the other eleven. Everyone had the same teacher, textbook, syllabus and course outlines. A graduate assistant was always present in class to note students' behaviour and interaction.

The PBL groups were given a problem on the first day of each new task and expected to present their findings to the class the following week. Presentations as well as a written report were submitted to the instructor a few days after the culmination of all presentations of a task. Table 1 lists the areas covered during the 14-week semester for the experimental and control groups.

Table 1. Distribution of topics per 2-week period for the course

\begin{tabular}{l}
\hline Weeks 1 \& 2: Introduction, Division of Groups and Pre-Tests \\
\hline Weeks 3 \& 4: English Pronunciation \\
\hline Weeks 5\& 6: Words and Lexical Structure \\
\hline Weeks 7 \& 8: On Meaning \\
\hline Weeks 9 \& 10: Phrase, Clause and Sentence structure \\
\hline Weeks 11 \& 12: Language in Context (Communication) \\
\hline Weeks $13 \&$ 14: Post-tests and Conclusion
\end{tabular}

The non-PBL group had lectures for each topic on the course outline and only one group assignment to be presented and submitted at the end of the semester. However, group work was assigned after the topic had been lectured, and discussed throughout the semester. Students in the non-PBL classes were also given sample literary pieces, in addition to those in the textbook, that the teacher discussed in class according to the topic of the week. The presentation and assignment followed the same format as the PBL group. However, the PBL group had to write comments and evaluations of the class at the end of the semester, particularly on the method and what they had learned. These were analysed for themes that would support the empirical data of the study.

\subsection{Assessment of Research Objectives}

To answer Research Question 1, that is acquisition of course content, the results of the final examination scores for both groups were analysed for similarities and differences, bearing in mind that the PBL group followed a self-learning structure via solving meaningful tasks, while the non-PBL had traditional lectures.

To answer Research Question 2, i.e. to determine the subjects' language progress, students of both PBL and non-PBL approaches sat the following tests:

1. An English Proficiency Test that consisted of a carefully constructed cloze tests, suited to the level of the students (advanced) at the beginning and end of the semester. The cloze test was chosen to test students' reading skills that might have improved following the PBL tasks.

2. Essay writing of approximately 500 to 800 words, at the beginning of the semester (pre-test) and end 
(post-test). The essays were graded for language and content, and subsequently the results of the two groups were compared and contrasted. An inter-rater, who is also an English instructor, evaluated the essays, according to the IIUM's Centre for Languages and Pre-University's marking scheme for writing in the university's English Placement Test.

\section{Finding and Discussion}

Although evaluations of the PBL groups were varied (peer and teacher evaluations, interviews, observations, pre-tests and post-tests), the discussion of the findings will only focus on the results of the pre-tests and post-tests of both groups for the cloze and essay, and the final examination scores. The pre-tests and post-tests were carried out to determine students' language improvements, while the final examination results were analysed to see the differences in performances between the PBL and non-PBL groups in terms of course content, i.e., with and without traditional instructions. Since the language tests were administered before the Final examination, the results in the following section are also presented in this order.

\subsection{Pre- and Post-Test Scores of PBL and non-PBL Groups for the Cloze Tests}

This section presents and discusses the results of the pre- and post-test scores of the PBL and non-PBL groups, which are shown in Table 1. The mean scores of the cloze results of both groups at the beginning of the semester were 9.36 and 9.25 for the non-PBL and PBL groups, respectively. The difference is not that marked $(0.11)$ which indicates that from the outset, the two groups, more or less, were at par in terms of their language abilities. The t-test for each group showed significance at $\mathrm{p}<0.005$.

Table 2. Performance of Experimental and Control Groups on the Cloze Test

\begin{tabular}{|c|c|c|c|c|}
\hline & \multicolumn{2}{|c|}{ Experimental Group } & \multicolumn{2}{|c|}{ Control Group } \\
\hline & Pre-Test & Post-Test & Pre-Test & Post-Test \\
\hline Mean (/20) & 9.36 & 13.35 & 9.25 & 10.70 \\
\hline n & 64 & 64 & 64 & 64 \\
\hline Std. dev. & 4.224 & 4.363 & 4.425 & 4.316 \\
\hline Std. error & .623 & .643 & .700 & .682 \\
\hline $\mathbf{r}$ & .848 & & .890 & \\
\hline $\mathbf{t}$ & -9.393 & & -2.931 & \\
\hline df & 45 & & 39 & \\
\hline Sig. (2-tailed) & $.000 *$ & & $.006^{*}$ & \\
\hline
\end{tabular}

* Significant difference

The results show that both groups show improvement in the cloze test. Particularly, the PBL approach has had a positive impact on the students' language skills in the cloze test, as they performed better in the post test, despite receiving minimal instructions in the classroom. In the post-test, the PBL group's mean score was 13.35, a difference of 3.99 from the pre-test. The non-PBL group, on the other hand, showed a mean score of 10.30 and a difference of 1.45 from the pre-test. The higher difference in mean score in the PBL group may be attributed to the extensive and critical reading students had to do on a variety of reading material throughout the semester in order to gather data to solve the PBL tasks. This was not done by the non-PBL group which received normal classroom instruction.

\subsection{The Written Tests}

The written tests, where students had to write on the same topic for both the pre- and post-tests, were given in the second and last week of the semester. The essays were evaluated by two teachers, to ensure scoring reliability, and were evaluated for language and organisation, and content (topic sentence, explanation and relevant examples). Analysis of individual essays show differences which were not marked enough, but when the results were aggregated according to the set categories of content and organisation, the differences were clearer, as shown in Tables 3 and 4. In terms of language and organisation, the essays were marked according to the overall language and structure of the essay, that is, in addition to a holistic scoring for language, the scoring also considered the presence of a clear introduction, a thesis or purpose statement, paragraphing of points, and a conclusion. Higher marks were awarded to students who showed efforts in using sub-topics to organise their essays. Lastly, content showed the presence of topic sentence/ideas, explanations and points which illustrate or elaborate the main points. T-tests were carried out for both groups; the results of the pre- and post-tests of the 
PBL group showed significance ( $\mathrm{p}<0.005)$, while the non-PBL group was not significant $(\mathrm{p}>0.005)$.

Table 3. Aggregated results of pre and post essay writing of PBL subjects

\begin{tabular}{llll}
\hline & Pre-test & Post-test & Difference \% \\
\hline Organisation & 425 & 508 & 19.5 \\
\hline Content & 82 & 168 & 104 \\
\hline
\end{tabular}

$\mathrm{n}=64 ; \mathrm{p}<0.005$ (significant)

Table 4. Aggregated results of pre and post writing of non-PBL subjects

\begin{tabular}{llll}
\hline & Pre-test & Post-test & Differences \% \\
\hline Organisation & 420 & 505 & 20.2 \\
\hline Content & 79 & 120 & 51.9 \\
\hline
\end{tabular}

$\mathrm{n}=64: \mathrm{p}>0.005$ (not significant)

The results were aggregated to show the differences in terms of content and organisation, which did not show in the individual results, as mentioned. The tables show that for both groups, none of the post-test scores are lower than the pre-test scores for the two categories, which indicated improvements for both groups. For the PBL group, we can see that in terms of organisation, the difference is slight at $19.5 \%$. The results stated thus far do not suggest marked improvements or differences between the groups. However, there is a marked difference in the content, in terms of the number of supporting points between the groups, which are $104 \%$ increase for the PBL group compared to $51.9 \%$ for the non-PBL group. Therefore, it would appear that students in the PBL group showed greater development in their content knowledge and writing skills and were able to present more arguments in their essays to support their points. As in the cloze test results, the improvements could have been due to the readings students were subjected to as well as the critical discussion and presentation of their data to the group after the reading.

The statistical results for the writing tests are as follows:

Table 5. Performance of Experimental and Control Groups in Essay Writing Test

\begin{tabular}{lllll}
\hline & \multicolumn{2}{l}{ Experimental Group } & \multicolumn{2}{l}{ Control Group } \\
\hline & Pre-Test & Post-Test & Pre-Test & Post-Test \\
\hline Mean (/20) & 7.04 & 9.54 & 8.43 & 8.53 \\
\hline $\mathbf{N}$ & 64 & 64 & 64 & 64 \\
\hline Std. dev. & 2.658 & 2.429 & 3.762 & 3.630 \\
\hline Std. error & .392 & .358 & .595 & .574 \\
\hline $\mathbf{R}$ & .847 & & .977 & \\
\hline $\mathbf{T}$ & -11.891 & & .781 & \\
\hline Df & 45 & & 39 & \\
\hline Sig. (2-tailed) & $.000^{*}$ & & .440 & \\
\hline
\end{tabular}

* Significant difference

The writing test was marked upon 20. The test for significance for the Experimental Group's performance $(p<0.000)$ shows that subjects in this group have improved as far as essay writing is concerned. However, there is no significant difference in the performance of the Control Group $(\mathrm{p}<0.440)$, that is, the subjects who were not exposed to PBL have not made any significant improvement in their performance in essay writing, with the mean showing only a slight improvement.

\subsection{Overall Course Grades}

This section reports on the course marks of the subjects of both the PBL and non-PBL groups as well as the final grade distribution of the two groups. This section is pertinent, to see the outcome of the PBL approach which, as mentioned earlier, involved no explicit classroom instruction on the topics and students must "acquire" the 
syllabus on their own via problem solving. The issue is whether the students were able to pick up the major points of the course via the interactive self-learning, problem-based approach. To reiterate, the PBL groups received no explicit instruction on the course topics, while the control group carried on with the traditional approach, i.e., full lectures for the various topics.

At the end of the semester, both the PBL and non-PBL groups sat for the same final examination paper at the same time. The marks for the final examination made up 40 percent of the course grade. For the PBL group, the PBL tasks provided the coursework mark of 60 percent. For the non-PBL group, the coursework marks were from the midterm and assignments. The results of both groups are tabulated in Table 6.0.

Table 6. Distribution of Course Marks / Grades of PBL and non-PBL group

\begin{tabular}{lllll}
\hline \multirow{2}{*}{ ccores } & PBL & \multicolumn{3}{c}{ Non-PBL } \\
\cline { 2 - 5 } & No of students & $\%$ & No of students & $\%$ \\
\hline $90-100$ & 0 & 0 & 2 & 3.2 \\
\hline $80-89$ & 4 & 6.3 & 5 & 7.8 \\
\hline $70-79$ & 10 & 15.6 & 6 & 9.5 \\
\hline $60-69$ & 19 & 29.7 & 16 & 25 \\
\hline $50-59$ & 26 & 40.6 & 22 & 34.5 \\
\hline $0-49$ & 5 & 7.8 & 13 & 20 \\
\hline
\end{tabular}

The results are presented according to grades distribution to see how the students performed overall, directed by concerns whether or not they have missed anything in the course content, and compared to those of the control group. The grades appear to show that the non-PBL group did slightly better than the PBL group, with two students scoring between 90 to 100 . In the PBL group, no one scored between $90-100 \%$. However, the PBL group shows fewer students in the lower ranges, 31 for ranges 0-49 and 50-59, while the non-PBL group shows 35. This shows the weaker students might have benefited from the PBL approach more than the better students, as only 5 students failed the course compared to 13 in the non-PBL group. We concluded that the overall difference, however, is not large enough to show that the PBL approach did better than the non-PBL approach or vice versa.

Despite this, did the PBL group acquire the course content? Since the results of the PBL group are similar to the non-PBL group, the answer is clear: the PBL group has acquired the course content in spite of minimal instruction. In fact, if we factor in the instructions that the non-PBL group received, the research would conclude that the PBL students had indeed done extremely well, as they did so on their own, without teacher guidance. In addition to this, students from the PBL group had also improved their language skills, compared to the non-PBL students. Therefore, the PBL method appears to be just as effective as the traditional method as far as content learning is concerned.

One of the major questions is whether the PBL approach is better than the traditional lecture approach. Mavis and Wagner (2006) compared PBL to traditional lectures by documenting medical students' opinions of the two methods of instruction. Students wrote positively for both methods. PBL was seen as encouraging interpersonal skills, while lectures were seen as efficient in learning. Overall, students in Mavis and Wagner's (2006) study preferred PBL as it was enjoyable and successful in achieving other organization goals/skills and life-long learning skills. In the current study, we showed that the lack of instruction did not impede learning and students were able to learn what they were supposed to, as evidenced by the results of the final examinations. However, PBL is one teaching approach out of many that may be useful in the teaching of English, particularly to non-native speakers, as it provides a meaningful reason or context to use the language. Given the fact that lesson plans are often varied and differ from one teacher to another and from one lesson to another, the researchers of the current study believe that there is no "right" way to teach language. Even if there have been studies, such as this one, conducted to demonstrate the effectiveness of one method over another, there are still other factors to consider. Some have been mentioned in the paper, which include the syllabus that one has to follow, the type of students, teacher training, general support, facilities and settings.

The idea of self-learning is not novel. The seminal work of Lev Semenovich Vygotsky on the concept of zone of proximal development (ZPD) was developed in late 1920s and ZPD is still being quoted frequently in current research, as seen in this example, which is: "the distance between the actual development level as determined by independent problem solving and the level of potential development as determined through problem solving 
under adult guidance or in collaboration with more capable peer" (Cole et al., 1980, p.86). The idea is that individuals learn best when collaborating with others, which also forms the basis of the PBL approach.

\section{Conclusion}

The overall results of the tests (cloze and written) show that the PBL group of the study were able to handle learning without explicit instruction and performed just as well as those in the traditional class. In terms of language, specifically in writing, students in the PBL group were also able to present their arguments in a more critical manner in the post-test essays and provided sufficient supporting material to illustrate their arguments. The non-PBL group, on the other hand, did not show marked differences in their language skills although they had the benefit of instructions and were guided throughout the semester by lectures. Given the "total" guidance, we expected students of the control group to perform better and show marked improvement in language skills. The reverse is true: the group that was left on their own did better. Thus, Malaysian language teachers should take note of this and not be overly worried about sacrificing course content when using the PBL approach in their classes.

Suggestions for future PBL language classes include the following: (1) to fit in all the course modules, each output of group discussion need not always be presented; a comprehensive written report for a few of the modules would suffice; (2) the teacher should assign more reading materials for each problem, for example, studying five different articles on a given topic which students may use to find solutions to their problems; and (3) use of Internet material should be accompanied by a printout of the site for teacher's perusal and to ensure the authenticity of students' work; (4) to consider the effects or role of the native language in students' discussions (Richards \& Rodgers, 2001).

As in all changes, a change from traditional-based lecture to the PBL approach would certainly face resistance from many sides. The first two are students who are already too familiar with the traditional lecture mode and thus would expect lectures, and teachers who are constrained by factors such as syllabus and time. However, Duch (1995) and the current study found that although there were initial resistance to the PBL approach, students eventually became highly motivated and, on another front, the teacher may look forward to new possibilities presented by the PBL approach every semester, and creating richer problems for the students to solve.

The concerns listed in this PBL study are also found in other language studies that use other approaches including the traditional approach: how to handle a large class, students using the native language, assessment, among others. Until now, there has not been much study on the issue of assessment of the PBL class. Most studies, such as this one, have focused on content (PBL versus non-PBL), although this is justifiable given that PBL is still in the experimental stage, particularly in the Human Sciences in Malaysia. Despite the usual problems one may encounter in handling the PBL method, it should still be tried out since our study has shown conclusively that students benefited from other positive effects of the approach in several ways: they communicated more, presented more critical arguments, while at the same time acquired the course content.

\section{References}

Allen, D. E., Duch, B. J., \& Groh, S. E. (1996). The power of problem-based learning in teaching introductory science courses. In L. Wilkerson, \& W.H. Gijselaers (Eds.), Bringing Problem-Based Learning to Higher Education: Theory and Practice (pp. 43-52). San Francisco: Jossey-Bass.

Anton, P. (1990). Student perceptions of problem-solving activities in an ESL classroom. TESOL Quarterly, 23, $3(1), 14-17$.

Barrows, H. S., \& Tamblyn, R. M. (1980). Problem-based learning: An approach to medical education. New York: Springer Pub. Co.

Boud, D. J., \& Feletti, G. I. (1994). Introduction. In D. J. Boud, \& G. I. Feletti (Eds.), The challenge of problem-based learning. London: Kogan Page.

Boud, D., \& G. Feletti. (1997). The Challenge of Problem Based Learning. London: Kogan Page.

Chen, C. M., \& Chia-Chi Chen, C. C. (2010). Problem-based learning supported by digital archives; Case study of Taiwan Libraries' History Digital Library. The Electronic Library, 28(1), 5. Oxford: 2010.

Chunta, K. S., \& Katrancha, E. D. (2010). Using Problem-Based Learning in Staff Development: Strategies for Teaching Registered Nurses and New Graduate Nurses. The Journal of Continuing Education in Nursing, 41(12), 557-565. http://dx.doi.org/10.3928/00220124-20100701-06

Cole, M., John-Steiner, V., Scribner, S., \& Souberman, Ellen. (1980). Mind in Society: Development of Higher Psychological Processes. Harvard: Harvard University Press. 
Copland, Michael. (2001). Speaking of Teaching. Stanford University Newsletter on Teaching, Winter 2001, $11(1)$.

Duch, Barbara J. (1995). The power of problem-based learning. A Newsletter of the Center for Teaching Effectiveness, January 1995. Retrieved October 20, 2004 from http://www.udel.edu/pbl/cte/spr96-bisc2.html

Eckerth, J., \& Siekmann, S. (eds.). (2008). Task-based language learning and teaching: Theoretical, methodological, and pedagogical perspectives. Frankfurt am Main: Peter Lang.

Huang, J. (2010). Grammar Instruction for Adult English Language Learners: A Task-Based Learning Framework. Journal of Adult Education, 39(1), 29-39. Brigham City.

Kam, P. W., \& Chi, B. L. (2007). Problem-based learning in social work: A study of student learning outcomes. Research on Social Practice, 17(1).

Lappalainen, P. (2010). Integrated language education - a means of enhancing engineers' social competences. European Journal of Engineering Education 35(4), 393. Abingdon. http://dx.doi.org/10.1080/03043797.2010.488290

Larsen-Freeman, D., \& Anderson, M. (2011). Techniques and Principles in Language Teaching (3rd Edition). Oxford: Oxford University Press.

Mardziah Hayati Abdullah. (2005). Problem-based learning in language instruction: A constructivist method. ERIC Clearinghouse on Reading, English, and Communication Digest \#132. Retrieved on April 26, 2005.

Mavis, B. E., \& Wagner, D. P. (2006). Comparing problem-based learning and lectures. Academic Exchange Quarterly, 10(4).

Ng, P. (2008). Promoting Problem-based Learning through Collaborative Writing. The English Teacher, MELTA, XXXVII, 49-60.

Nor Hartini Saari. (2006). Unemployed graduates: How can we address this situation? Retrieved December 30, 2006 from http://www.ikim.gov.my/v5/index.php?lg=1\&opt=com_article\&grp=2\&sec=\&key=1482\&cmd $=$ resetall

Richards, J., \& Rodgers, T. (2001). Approaches and methods in language Teaching (2nd ed.). Cambridge: Cambridge University Press. http://dx.doi.org/10.1017/CBO9780511667305

Shih, K. T., Chiang, L. J., Huang, M. Y., Ting, T. M., \& Lin, C. J. (2007). Problem-based learning on critical thinking and movement skill performance in elementary physical education. Research Quarterly for Exercise and Sport, 78, 1.

Ting, S. H., Mahanita Mahadhir, \& Chang, S. L. (2010). Grammatical Errors In Spoken English Of University Students In Oral Communication Course. GEMA Online ${ }^{\mathrm{TM}}$ Journal of Language Studies, 10(1).

Tan, Oon Seng. (2003). Problem-based learning innovation. Singapore: Thomson.

Toth, P. D. (2008). Teacher- and Learner-Led Discourse in Task-Based Grammar Instruction: Providing Procedural Assistance for L2 Morphosyntactic Development. Language Learning, Ann Arbor, 58(2), 237.

Watson, George. (2001). Problem-based learning. Speaking of Teaching, 11(1), 1-7.

White, H. B. (1996). Dan tries problem-based learning: A case study. In L. Richlin (Ed.), To Improve the Academy, 15, 75-91.

Zaharuddin Abd. Rahman. (2007). Temuduga kerja: Apa kunci kejayaannya? Retrieved 7 November, 2007 from http://www.zaharudd in.net/.

\section{Notes}

Note 1. G. Watson presented a seminar on PBL to the academic staff of IIUM in 2001.

\section{Appendix: Samples of task/problem}

\section{Problem 1}

You have been assigned to a group that will visit an aboriginal village in Kuala Selangor. One of the activities there would be to teach English to the primary school children in two after school sessions that would take two hours per session. Your group will be focusing on English pronunciation. Prepare lessons with plenty of activities for the children to learn English pronunciation. Your group may narrow the focus to a few sound units. At presentation time, you should submit a report justifying your selection of sound units and your method of 
'teaching'.

\section{Problem 2}

Your team has been hired to design a publicity advertisement for a product (for the task, you may choose the product). In the task, you should study rival advertisements in order to produce effective work that would satisfy your client. Each morpheme, word, phrase or sentence used must be stylistically relevant to the product and the message you are trying to put forth. At presentation time, you should submit the advertisement and a short report justifying your choice of words. 